\title{
Adrenergic Gating of Hebbian Spike-Timing-Dependent Plasticity in Cortical Interneurons
}

\author{
Shiyong Huang, ${ }^{1}$ Richard L. Huganir, ${ }^{2}$ and Alfredo Kirkwood ${ }^{1,2}$ \\ ${ }^{1}$ Mind/Brain Institute, Johns Hopkins University, Baltimore, Maryland 21218, and ${ }^{2}$ Department of Neuroscience, Johns Hopkins University, Baltimore, \\ Maryland 21205
}

In pyramidal cells, the induction of spike-dependent plasticity (STDP) follows a simple Hebbian rule in which the order of presynaptic and postsynaptic firing dictates the induction of LTP or LTD. In contrast, cortical fast spiking (FS) interneurons, which control the rate and timing of pyramidal cell firing, reportedly express timing-dependent LTD, but not timing-dependent LTP. Because a mismatch in STDP rules could impact the maintenance of the excitation/inhibition balance, we examined the neuromodulation of STDP in FS cells of mouse visual cortex. We found that stimulation of adrenergic receptors enables the induction of Hebbian bidirectional STDP in FS cells in a manner consistent with a pull-push mechanism previously characterized in pyramidal cells. However, in pyramidal cells, STDP induction depends on NMDA receptors, whereas in FS cells it depends on mGluR5 receptors. We propose that neuromodulators control the polarity of STDP in different synapses in the same manner, and independently of the induction mechanism, by acting downstream in the plasticity cascade. By doing so, neuromodulators may allow coordinated plastic changes in FS and pyramidal cells.

\section{Introduction}

Modification of synaptic strength based on the correlation between presynaptic and postsynaptic firing is considered essential for the processes of learning, memory formation, and cortical refinement. An attractive model for the induction of these modifications in vitro is spike-timing-dependent plasticity (STDP) of near-coincidental presynaptic and postsynaptic firing (Song et al., 2000; Song and Abbott, 2001; Dan and Poo, 2004; Richards et al., 2010). In the excitatory inputs to pyramidal cells, where the mechanisms of STDP have been worked out in great detail, the induction of STDP largely follows the Hebbian rule (Markram et al., 2011; Feldman, 2012). Typically, presynaptic firing preceding postsynaptic firing induces long-term potentiation (LTP), whereas postsynaptic firing before presynaptic firing induces long-term depression (LTD). In contrast, a large diversity of coincidence rules for STDP has been described in the excitatory inputs onto inhibitory interneurons (Fino and Venance, 2010; Lamsa et al., 2010; Kullmann et al., 2012). This diversity of rules for plasticity of excitatory inputs onto interneurons, which is comparable to the diversity of plasticity of their inhibitory outputs (Castillo et al., 2011), has been interpreted in terms of the functional heterogeneity of interneuron types (Kullmann et al., 2012), which form a highly diverse group in terms of anatomy,

Received Dec. 15, 2012; revised June 27, 2013; accepted July 8, 2013.

Author contributions: S.H. designed research; S.H. performed research; R.H. contributed unpublished reagents/ analytic tools; S.H. analyzed data; S.H. and A.K. wrote the paper.

This work was supported by National Eye Institute Grant R01 EY012124 to A.K. We thank Drs. H.K. Lee and J. Whitt for valuable comments on the manuscript.

The authors declare no competing financial interests.

Correspondence should be addressed to Dr. Alfredo Kirkwood, Department of Neuroscience, Mind/Brain Institute, Johns Hopkins University, Dunning Hall 350, 3400 N. Charles Street, Baltimore, MD 21218. E-mail: Kirkwood@jhu.edu.

DOI:10.1523/JNEUROSCI.5741-12.2013

Copyright $\odot 2013$ the authors $\quad 0270-6474 / 13 / 3313171-08 \$ 15.00 / 0$ molecular markers, and somatic excitability (Huang et al., 2007; Ascoli et al., 2008). Indeed, an emerging consensus is that the plasticity rules of excitatory inputs onto interneuron inputs are cell-type specific (Kullmann et al., 2012). For example, in cortex, inputs from pyramidal cells onto low threshold interneurons reportedly exhibit bidirectional STDP, whereas inputs onto fast spiking (FS) basket cells only exhibit spike timing LTD (tLTD) (Lu et al., 2007).

The absence of spike timing LTP (tLTP) in cortical FS cells is intriguing. FS cells are the most abundant interneuron subtype (Xu et al., 2010) and provide the bulk of feedforward and feedback inhibition that constrains cortical excitability (Freund and Katona, 2007). Robust tLTD unbalanced by tLTP suggests that cortical activity will tend to depress the excitatory drive onto FS cells, which could potentially lead to a positive feedback loop in which increased cortical activity reduces the recruitment of FS cells. This type of consideration prompted us to reexamine STDP in FS cells. We asked whether neuromodulators, which gate the induction of bidirectional STDP in cortical pyramidal cells (Seol et al., 2007), could also control STDP in interneurons. We found that activation of $\alpha 1$ - and $\beta$-adrenergic receptors enabled the induction of Hebbian bidirectional STDP in fast-spiking parvalbumin (PV) positive interneurons and in somatostatin (SOM) positive low threshold interneurons. Notably, similar rules govern the neuromodulation of STDP in interneurons and in pyramidal cells, even though the induction mechanisms are markedly different: STDP depends on NMDAR activation in pyramidal cells, whereas in FS interneurons it depends on type I mGluRs. These findings suggest that the rules previously characterized in pyramidal cells might be a general principle governing the neuromodulation of synaptic plasticity in a diversity of synapses. 


\section{Materials and Methods}

Visual cortical slices $(300 \mu \mathrm{m})$ were prepared as described previously (Jiang et al., 2010b) from P21-P25 G42 and GIN mice, of either sex, that express GFP in parvalbumin-positive and SOM-positive cells, respectively. Briefly, slices were cut in ice-cold dissection buffer containing the following (in mM): 212.7 sucrose, $5 \mathrm{KCl}, 1.25 \mathrm{NaH}_{2} \mathrm{PO}_{4}, 10 \mathrm{MgCl}_{2}, 0.5$ $\mathrm{CaCl}_{2}, 26 \mathrm{NaHCO}_{3}$, and 10 dextrose, bubbled with $95 \% \mathrm{O}_{2} / 5 \% \mathrm{CO}_{2}, \mathrm{pH}$ 7.4. Individual slices were transferred to normal artificial CSF (ACSF) for at least $1 \mathrm{~h}$ before recording. Normal ACSF is similar to the dissection buffer, except that sucrose is replaced by $124 \mathrm{~mm} \mathrm{NaCl}, \mathrm{MgCl}_{2}$ is lowered to $1 \mathrm{~mm}$, and $\mathrm{CaCl}_{2}$ is raised to $2 \mathrm{~mm}$. One cell per slice was used.

Electrophysiology. Interneurons in layer II/III were identified by positive fluorescence, and subtype classification was confirmed through electrophysiological properties. Visualized whole-cell current-clamp recordings were made using a MultiClamp 700A amplifier (Molecular Devices). Borosilicate glass recording pipettes $(4-6 \mathrm{M} \Omega$ ) were filled with intracellular solution containing (in $\mathrm{mm}$ ) as follows: 130 (K)gluconate, $10 \mathrm{KCl}$, 0.2 EGTA, 10 HEPES, $4(\mathrm{Mg})$ ATP, $0.5(\mathrm{Na}) \mathrm{GTP}$, and $10(\mathrm{Na})$ phosphocreatine ( $\mathrm{pH}$ adjusted to 7.25 with $\mathrm{KOH}, 280-290 \mathrm{mOsm}$ ). Only cells with membrane potentials more negative than $-65 \mathrm{mV}$, series resistance $<20 \Omega$ were studied. Cells were excluded if input resistance changed $>15 \%$ over the entire experiment, with the exception of changes during bath application of the agonists. Data were filtered at $2 \mathrm{kHz}$ and digitized at $10 \mathrm{kHz}$ using Igor Pro (WaveMetrics).

Two concentric bipolar stimulating electrodes (FHC) were placed 1 $\mathrm{mm}$ apart at layer IV opposite to recorded neurons. Pathway independence was verified by linear summation of the responses and absence of paired pulse interactions (see Fig. 1). Synaptic responses were evoked with $0.02 \mathrm{~ms}$ paired pulses ( $100 \mathrm{~ms}$ interval) delivered every $10 \mathrm{~s}$ to both pathways in an alternating manner. Stimulation intensity was adjusted to evoke 4-6 $\mathrm{mV}$ responses. Synaptic strength was quantified as the initial slope (the first $2 \mathrm{~ms}$ ) of the EPSP. Mean baseline slope was calculated from 30 consecutive sweeps before the start of drug application. tLTP and tLTD were attempted by pairing presynaptic stimulation (in layer IV) with postsynaptic burst firing evoked by four brief suprathreshold current pulses (2 ms duration, $10 \mathrm{~ms}$ apart, 1.5 times threshold current). Pre-then-post and post-then-pre STDP epochs were applied in two independent pathways converging onto the same cell. As shown in Figure 1, the pre-then-post pathway consisted of presynaptic stimulation preceding postsynaptic firing, whereas for the post-then-pre pathway presynaptic stimulation followed postsynaptic firing. The interval between presynaptic and postsynaptic firing was always $10 \mathrm{~ms}$. These pairing epochs were delivered for $200 \mathrm{~s}$ at $1 \mathrm{~Hz}$.

Methoxamine and isoproterenol were purchased from Sigma. 2-Methyl6-(phenylethynyl) pyridine hydrochloride (MPEP), DL-threo- $\beta$-benzyloxyaspartic acid (TBOA), and 2-amino-5-phosphonopentanoic acid (APV) were purchased from Tocris Bioscience. Isoproterenol and methoxamine were applied in conjunction with sodium ascorbate $(40 \mu \mathrm{M})$ to prevent oxidation of the drugs. Only data from slices with stable recordings $(<5 \%$ change over the baseline period) were included in the final analysis. All data are presented as average \pm SEM normalized to the preconditioning baseline. For comparisons, the LTD or LTP magnitude was taken as the average of the last $5 \mathrm{~min}$ recorded (35-40 min in the case of PV-FS cells; 25-30 min in the case of SOM cells).

Statistical analysis. The significance of LTP and LTD was assessed using the paired Student's $t$ test. Other comparisons used unpaired $t$ test or the ANOVA test. $p<0.05$ was considered statistically significant.

\section{Results}

Coactivation of $\alpha 1$ - and $\beta$-adrenergic receptors enables bidirectional Hebbian STDP in FS-PV interneurons

Multiple STDP rules have been described for different interneuron types in different brain regions (Fino and Venance, 2011; Kullmann et al., 2012). Despite this diversity, in cortex STDP paradigms reportedly only induce LTD, never LTP, in excitatory inputs onto layer II/III FS interneurons ( $\mathrm{Lu}$ et al., 2007). We previously showed in the excitatory inputs onto pyramidal cells that the same STDP paradigm results in multiple outcomes de- pending on the balance of neuromodulators. This neuromodulation of STDP follows a simple pull-push rule: Gs-coupled receptors promote LTP at the expense of LTD, whereas Gq/11coupled receptors promote LTD at the expense of LTP (Seol et al., 2007; Zhang et al., 2009). Therefore, we set out to determine whether neuromodulators enable bidirectional STDP (LTP and LTD) in FS interneurons and whether a pull-push mechanism dictates a diversity of STDP outcomes.

To address this question, our initial studies were done in visual cortical slices from G42 mice (Chattopadhyaya et al., 2004), which express GFP only in fast-spiking parvalbumin positive (FS$\mathrm{PV}$ ) interneurons. We used $\beta$ - and $\alpha 1$-adrenergic receptors as models for Gs- and Gq/11-coupled receptors, respectively. For comparative purposes, STDP was studied with the same paradigms we previously reported for pyramidal cells (Seol et al., 2007; Guo et al., 2012): two pathways were independently stimulated shortly before or shortly after a burst of postsynaptic action potentials (Fig. 1A). In the first round of experiments, conditioning consisted of stimulating one pathway $10 \mathrm{~ms}$ before postsynaptic firing (pre-then-post), which often induces LTP in many Hebbian synapses. Conversely, the other pathway was stimulated $10 \mathrm{~ms}$ after postsynaptic firing (post-then-pre), a paradigm that often induces LTD. None of the pairings induced significant changes in the EPSPs $(95 \pm 13 \%$ of baseline at $30 \mathrm{~min}$ after conditioning in the pre-then-post pathway, $p=0.68 ; 91 \pm$ $6 \%$ in the post-then-pre pathway, $p=0.16 ; n=14$; Fig. $1 B$ ). Thus, as we previously reported for pyramidal cells, under these experimental conditions the excitatory inputs to FS-PV are not modified by standard STDP protocols.

Next, we examined whether stimulation of $\beta$-adrenergic receptors (coupled to Gs) and $\alpha 1$-adrenergic receptors (coupled to $\mathrm{Gq} / 11$ ) in conjunction with STDP protocols enable the induction of LTP and LTD in FS-PV cells as predicted by the pull-push model (Seol et al., 2007; Huang et al., 2012). In these experiments, the STDP pairings (pre-then-post to induce LTP, or post-thenpre to induce LTD; $10 \mathrm{~ms}$ delay in both cases) were selectively delivered to one pathway after a $10 \mathrm{~min}$ bath application of either the $\beta$-adrenergic agonist isoproterenol (Iso: $10 \mu \mathrm{M}$ ) or the $\alpha 1$ adrenergic agonist methoxamine (Met: $10 \mu \mathrm{M})$. The nonconditioned pathway served as a control for any long-term effects of the agonists. The results are shown in Figure $1 C, D$. STDP conditioning delivered at the end of the isoproterenol application induced a robust LTP in the conditioned pathway only (conditioned, $132 \pm 15 \%, p=0.045$; nonconditioned, $102 \pm 9 \%, p=0.98 ; n=$ 14 ; Fig. $1 C$ ). The induction of LTP was not associated with changes in the input resistance (104 $\pm 4 \%$ of baseline), or with changes in paired pulse depression $(100 \pm 3 \%, p=0.87)$, which is an indicator of presynaptic changes. In a similar fashion, the application of methoxamine promoted the induction of a homosynaptic form LTD (conditioned, $59 \pm 5 \%, p<0.001$; nonconditioned, $96 \pm 4 \%, p=0.51, n=10$; Fig. $1 D)$ that was not associated with changes in input resistance (109 $\pm 4 \%$ of baseline) or paired pulse facilitation $(96 \pm 9 \%, p=0.92)$. These results indicate that the activation of $\beta$ - and $\alpha 1$-adrenergic receptors respectively promotes the induction of homosynaptic and postsynaptic forms of LTP and LTD in FS-PV cells.

According to the pull-push model of neuromodulation tipping, the Gs/Gq11 balance toward Gs, by stimulation of $\beta$-adrenergic receptors, for example, should result in a state where only LTP is induced regardless of the order of presynaptic and postsynaptic firing (Seol et al., 2007; Huang et al., 2012). Conversely, stimulation of $\alpha 1$-adrenergic receptors should promote an LTD-only state. To examine this possibility, we tested 
A
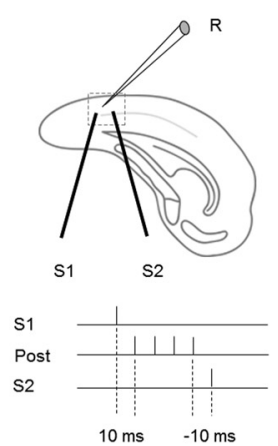

C

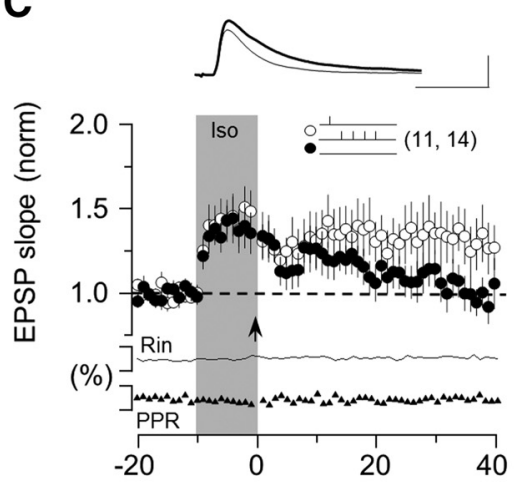

E

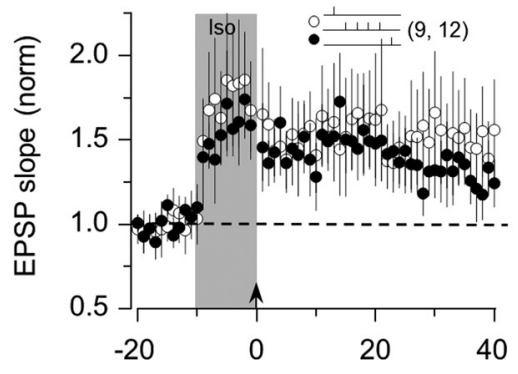

Time after stimulation $(\mathrm{min})$

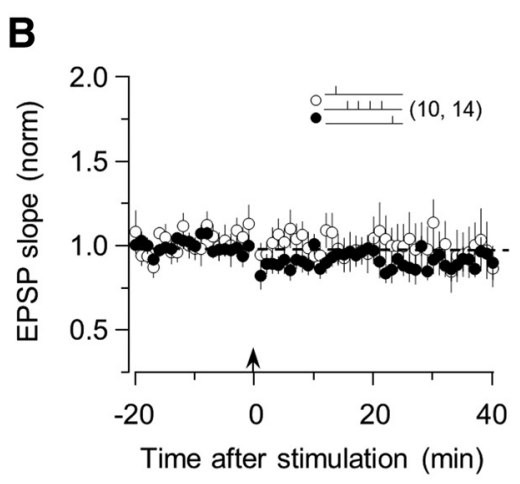

D

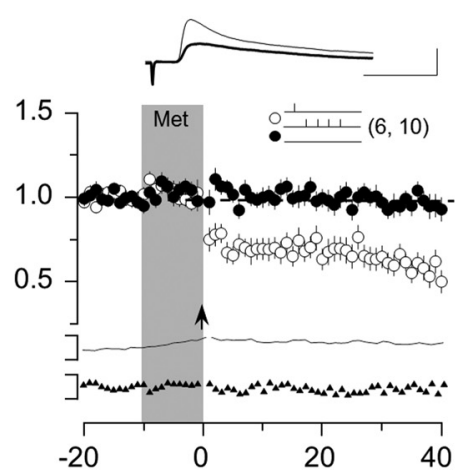

$\mathbf{F}$

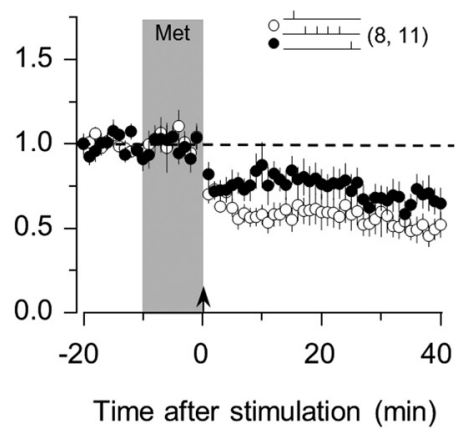

Figure 1. $\quad \beta$ - and $\alpha 1$-adrenergic agonist enables associative LTP and LTD. $\boldsymbol{A}$, Experimental schematics. Top, EPSPs were recorded in layer II/III PV interneurons by stimulating the underlying layer IV at two sites (S1 and S2). Bottom, Conditioning paradigm. During each pairing epoch (200 at $1 \mathrm{~Hz}$ ), stimulation of one or both pathways was paired with a postsynaptic burst of four action potentials ( $100 \mathrm{~Hz}$ ). $\boldsymbol{B}$, In control ACSF, the pairing paradigm (arrow) does not affect the EPSPs. C, Brief application of the $\beta$-agonist isoproterenol (Iso: $10 \mu \mathrm{m}, 10 \mathrm{~min}$; gray bar) promotes the induction of homosynaptic LTP. $\boldsymbol{D}$, The $\alpha 1$-agonist methoxamine (Met: $5 \mu \mathrm{m}, 10 \mathrm{~min}$; gray bar) promotes the induction of homosynaptic LTD. In both cases, the polarity of plasticity was independent of the order of presynaptic and postsynaptic activation. Only LTP was induced with isoproterenol (E), and only LTD with methoxamine $(\boldsymbol{F})$. The number of experiments is indicated in parentheses. $\boldsymbol{C}, \boldsymbol{D}$, Superimposed traces are averages of 10 consecutive responses recorded right before (thin line) and $30 \mathrm{~min}$ after conditioning (thick line). Calibration: $2 \mathrm{mV}, 10 \mathrm{~ms}$. Note the absence of changes in the normalized paired-pulse ratio and membrane input resistance (Rin), which are displayed below $\boldsymbol{A}$ and $\boldsymbol{B}$. Data are mean \pm SEM.

both timing sequences in the same cells by stimulating one pathway $10 \mathrm{~ms}$ before and the other one $10 \mathrm{~ms}$ after the postsynaptic burst. As shown in Figure 1E, F, in the presence of isoproterenol, LTP was induced in both pathways (pre-then-post, $150 \pm 25 \%$, $p=0.024$; post-then-pre, $130 \pm 14 \%, p=0.025 ; n=12$ ), whereas in the presence of methoxamine, LTD was induced in both pathways (pre-then-post, $51 \pm 6 \%, p<0.001$; post-thenpre, $67 \pm 7 \%, p<0.001 ; n=11)$. Thus, in accordance with the pull-push model, in FS-PV cells, the activation of a single receptor type promotes synaptic changes in one polarity only.

The pull-push model further predicts that bidirectional STDP requires balanced activation of neuromodulatory receptors cou-

pled to Gs and Gq/11 (Seol et al., 2007). Therefore, we tested whether coapplication of Iso $(10 \mu \mathrm{M})$ and Met $(10 \mu \mathrm{M})$, to coactivate $\beta$ and $\alpha 1$ receptors, enables bidirectional STDP in FS-PV cells. In these experiments, we tested both the pre-thenpost and the post-then-pre spike timing sequences (with a $10 \mathrm{~ms}$ delay) in the same cell as described above (Fig. $1 B$ ). As shown in Figure $2 A$, in the presence of Iso and Met, the conditioning pairing induced LTP or LTD in a Hebbian manner depending on the spike timing (pre-thenpost, $136 \pm 12 \%, p=0.009$; post-thenpre, $72 \pm 6 \% ; p=0.004 ; n=11)$. STDP stimulation did not affect pair-pulse depression in either pathway (pre-thenpost, $105 \pm 7 \%, p=0.36$; post-then-pre, $101 \pm 12 \%, p=0.08)$, confirming that the locus for LTP and LTD expression is postsynaptic. The results indicate that the timing sequence of presynaptic and postsynaptic activation determines the polarity of the STDP when gated by coactivation of $\beta$ and $\alpha 1$ receptors. We further evaluated the timing-dependency of this form of plasticity by varying the delay between presynaptic and postsynaptic activation. The results, shown in Figure $2 B$, revealed two approximately symmetrical time windows for the induction of LTP and LTD. In both cases the peak occurs at $\sim+/-10$ $\mathrm{ms}$ and the window width is less that 50 $\mathrm{ms}$, which is highly reminiscent of the shape for neuromodulator-gated STDP in pyramidal cells (Seol et al., 2007).

Next, we investigated the developmental changes of adrenergically gated STDP in FS-PV cells. In several cortical synapses, including inhibitory synapses made by FS-PV cells, activity-dependent plasticity can be induced only during an early critical period, which terminates at or before the fifth week of age (Feldman et al., 1999; Morales et al., 2002; Jiang et al., 2007, 2010b). On the other hand, tetanusinduced LTP of excitatory inputs onto FS-PV cells is reportedly equally robust at 3 and 5 weeks of age (Jiang et al., 2010a). Therefore, we measured the peak magnitude of LTP and LTD (evoked with $10 \mathrm{~ms}$ delays in the presence of Iso and Met) in slices from mice 3, 5, and 8 weeks old. For both LTP and LTD, the magnitude of plasticity was comparable at 3 and 5 weeks of age and virtually null at 8 weeks of age (Fig. 2C; LTP: $136 \pm 12 \%, 140 \pm 23 \%$, and $108 \pm$ $6 \%$ at 3, 5, and 8 weeks, respectively; LTD: $72 \pm 6 \%, 81 \pm 12 \%$, and $91 \pm 12 \%$ at 3,5 , and 8 weeks, respectively; the 3 week data are the same as in Fig. $3 A$ ). These results indicate that, in FS-PV cells, there is a prolonged critical period for STDP that terminates later than other maturational processes in the visual cortex.

Finally, we examined the adrenergic modulation of STDP in FS-PV cells in the somatosensory cortex. It was previously reported that the FS-PV cells of this region only express tLTD (Lu et 
al., 2007). As shown in Figure 2D, coapplication of Iso and Met allowed the induction of both tLTP and tLTD in a spike timing-dependent manner (pre-thenpost, $120 \pm 6 \%, p=0.014$; post-then-pre, $64 \pm 8 \% ; p=0.003 ; n=9)$. These results suggest that the principles governing noradrenergic gating of bidirectional STDP are applicable beyond the visual cortex.

\section{Metabotropic glutamate receptors mediate STDP in FS-PV cells}

We investigated the induction mechanisms of postsynaptic STDP in FS-PV cells in the visual cortex. In pyramidal cells, the induction of postsynaptic Hebbian STDP depends on the activation of NMDARs, which serve as the coincidence detector for presynaptic and postsynaptic activation. However, in FS-PV cells, the induction of LTP and LTD has been reported to depend on the type I metabotropic glutamate receptors mGluR5, not NMDARs (Sarihi et al., 2008). Therefore, we examined the role of NMDARs and mGluRs in noradrenergic-gated STDP by testing how antagonists to NMDARs (APV, $100 \mu \mathrm{M})$ and mGluR5 (MPEP, 10 $\mu \mathrm{M})$ affected the induction of tLTP and tLTD. Bath application of APV did not block t-LTP promoted by Iso (pre-thenpost, $134 \pm 15 \%, p=0.041$; post-thenpre, $141 \pm 11 \%, p=0.002 ; n=13$; Fig. $3 A)$, nor did it block the induction of tLTD promoted by Met (pre-then-post, $52 \pm 9 \%, p=0.002$; post-then-pre, $73 \pm 8 \%, p=0.014 ; n=9$; Fig. $3 B$ ), indicating that NMDA receptor activation is not required for the induction of STDP in FS-PV cells. To test the effects of bath application of MPEP $(10 \mu \mathrm{M})$, we measured tLTP and tLTD in the same cells for both pathways by coapplying Iso and Met. MPEP blocked the induction of lasting changes in both pathways (pre-then-post, $96 \pm 8 \%, p=0.35$; post-then-pre, $96 \pm 11 \%, p=0.59 ; n=12$; Fig. $3 C$ ), indicating that mGluR5 activation is essential for the induction of STDP on FS-PV interneurons. Finally, we evaluated the role of intracellular $\mathrm{Ca}^{2+}$ concentration increases and found that the inclusion of BAPTA, a $\mathrm{Ca}^{2+}$ buffer, in the recording pipette (10 mM BAPTA) was sufficient to prevent the induction of STDP (pre-then-post, $93 \pm 10 \% ; p=0.27$; post-then-pre, $107 \pm$ $7 \%, p=0.20 ; n=6$ in Iso and Met; data not shown).

In pyramidal cells, neuromodulators promote STDP by phosphorylating AMPA receptors at sites that are essential for trafficking the receptors in and out of the synapse (Lee and Kirkwood, 2011). Previously, we reported that pyramidal cells in mice in which serine 831 of GluA1 subunit is changed to alanine (S831A mice) to prevent phosphorylation do not express tLTD, although they exhibit tLTP (Seol et al., 2007). Therefore, we crossed the S831A and the G42 lines to evaluate the possible role of AMPAR phosphorylation in the neuromodulation of STDP in FS-PV cells. In these experiments, we used mice that are homozygous for S831A to test tLTP and tLTD in both independent pathways. As shown in Figure 3D, tLTD was impaired in S831A individuals, whereas tLTP was induced in both pathways, regardless of spiketiming order (pre-then-post, $133 \pm 8 \%, p=0.016$; post-then- pre, $128 \pm 9 \% ; p=0.047 ; n=12$ ), indicating that the phosphorylation of the 831 site is essential for the induction of tLTD in FS-PV neurons.

In CA1 hippocampal synapses, neuromodulators can promote STDP in a presynaptic manner by enhancing stimulusinduced glutamate release (Gu et al., 2011; Gu and Yakel, 2012). To test whether this occurs in FS-PV interneurons, we blocked glutamate transporters with DL-TBOA to enhance glutamate levels at the synaptic cleft and examined whether this mimicked adrenergic gating of bidirectional STDP. Consistent with increased glutamate levels, bath application of TBOA $(5 \mu \mathrm{M})$ rapidly increased the EPSC amplitude in FS-PV interneurons (145 \pm $9 \%, p=0.007 ; n=5$; Fig. $3 E$ ). However, $10 \mathrm{~min}$ application of TBOA did not promote the induction of STDP (pre-then-post, $95 \pm 4 \%, p=0.235$; post-then-pre, $98 \pm 7 \% ; p=0.777 ; n=7$; Fig. $3 F$ ), indicating that the noradrenergic gating of STDP does not involve the enhancement of presynaptic glutamate release.

\section{Adrenergic neuromodulation of STDP in SOM interneuron}

Non-fast-spiking SOM-positive cells are the second most common interneuron type in neocortex (Xu et al., 2010). Several studies have reported different induction rules for STDP in SOM and FS cells (Lu et al., 2007; Chen et al., 2009). We used the GIN mouse line, which expresses GFP in SOM cells (Oliva et al., 2000) to test whether neuromodulation of STDP in these cells is similar to pyramidal and FS-PV cells. First, we used the same protocols described previously (Figs. $1 B$ and $2 A$ ) to test tLTD and tLTP in both pathways in the same cells. As shown in Figure 4, after 10 min coapplication of Iso and Met, tLTP and tLTD were induced 
A

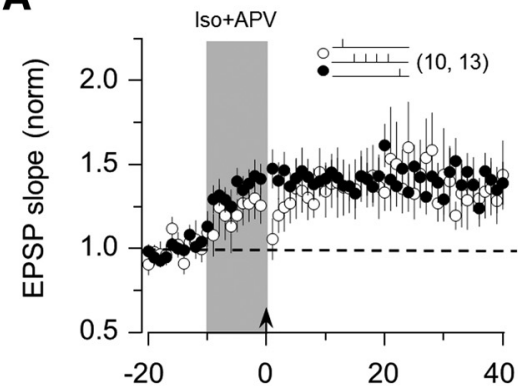

C

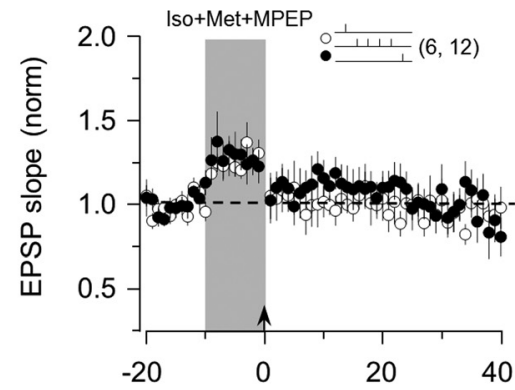

Time after stimulation ( $\mathrm{min})$

E

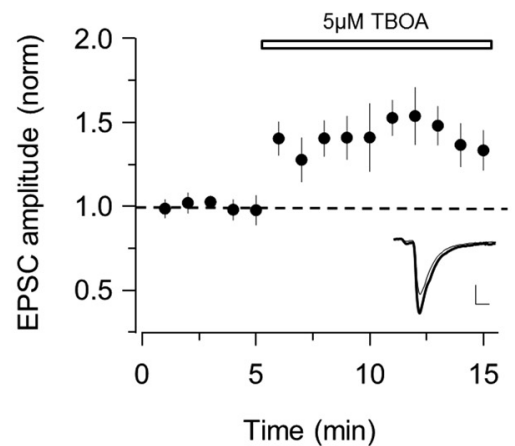

B

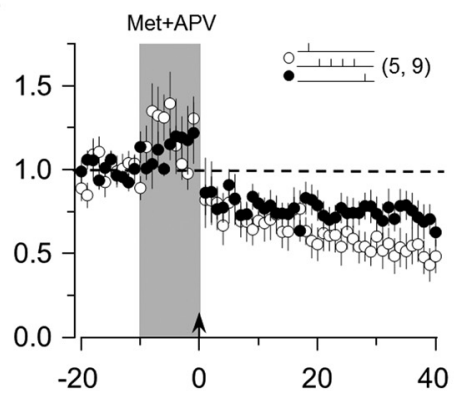

D

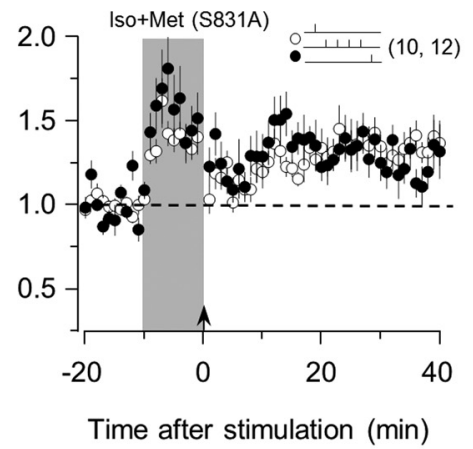

$\mathbf{F}$

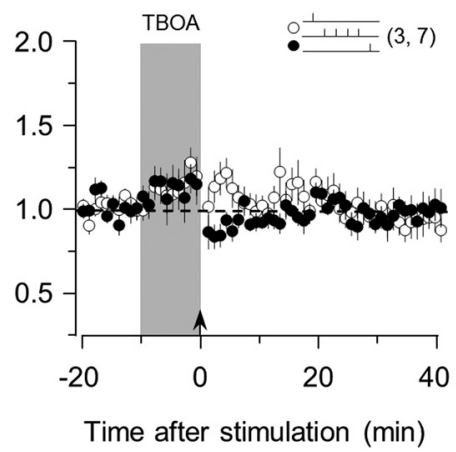

Figure 3. Mechanisms of STDP in PV interneurons. Bath application of the NMDA receptor antagonist APV (100 $\mu \mathrm{m})$ does not block the induction of either tLTP $(\boldsymbol{A})$ or tLTD $(\boldsymbol{B})$. C, Bath application of the mGluR5 antagonist MPEP (10 $\mu$ M) blocks STDP. D, Absence of tLTD and normal tLTP in GluR1 S831A mutant mice. $\boldsymbol{E}$, Bath application of the glutamate transporter inhibitor TBOA (5 $\mu \mathrm{M}$ ) increases EPSC amplitude. $\boldsymbol{F}$, TBOA $(5 \mu \mathrm{m})$ does not enable the bidirectional STDP. Superimposed traces in $\boldsymbol{E}$ are averages of 10 consecutive responses recorded right before (thin line) and $5 \mathrm{~min}$ after TBOA application (thick line). The number of experiments is indicated in parentheses. Data are mean \pm SEM.

in both pathways in a spike timing-dependent manner (pre-thenpost, $119 \pm 6 \%, p=0.02$; post-then-pre, $74 \pm 5 \%, p<0.001 ; n=$ 12; Fig. $4 A$ ). In both cases, the paired pulse ratio was not affected $(p=0.64$ for tLTD; $p=0.91$ for tLTP), consistent with a postsynaptic locus of expression. In contrast, in the absence of experimentally added neuromodulators, STDP conditioning did not affect the responses (pre-then-post, $87 \pm 9 \%, p=0.11$; postthen-pre, $104 \pm 15 \%, p=0.55 ; n=10$; data not shown). Similarly, coapplication of Iso and Met paired with postsynaptic firing only did not induce significant changes $(101 \pm 3 \%, p=0.667$; $n=12$; Fig. $4 A$ ).

To further characterize STDP in SOM interneurons, we evaluated the timing dependency of this form of plasticity by varying the delay between presynaptic and postsynaptic activation (as in Fig. 2B). STDP in SOM interneurons exhibited a spike-time window that was $<50 \mathrm{~ms}$ for both tLTP and tLTD and comparable with that observed in FS-PV interneurons (Fig. 4B). We also confirmed that $\beta$-adrenergic activation promotes an LTP-only state, similar to the effects of $\beta$-adrenergic activation in pyramidal and FS-PV cells. In the presence of $10 \mu \mathrm{M}$ Iso, both the pre-then-post and the post-then-pre pairings resulted in comparable tLTP (pre-then-post, $136 \pm 12 \%$, $p=0.042$; post-then-pre, $132 \pm 6 \%, p=$ $0.004 ; n=5$; Fig. $4 C$ ). Finally, we found that, unlike in FS-PV cells, but similar to pyramidal neurons, the induction of bidirectional STDP in SOM neurons depends on NMDA receptors (Lu et al., 2007) and that addition of NMDAR antagonist $\operatorname{APV}(100 \mu \mathrm{M})$ to the bath prevented the induction of STDP (pre-then-post, $99 \pm$ $13 \%, p=0.931$; post-then-pre, $93 \pm 5 \%$, $p=0.258 ; n=7$; Fig. $4 C$ ).

For comparative purposes, the STDP pairings were designed with bursts of 4 action potentials at $100 \mathrm{~Hz}$. However, in vivo the average firing rates of SOM cell are much lower. Therefore, we tested the induction of STDP with other regimens of postsynaptic action potentials. As shown in Figure $4 D$, reducing either the rate (from $100 \mathrm{~Hz}$ to $30 \mathrm{~Hz}$ ) or the number of the action potentials (from 4 to 1 ) in the pairings did not prevent STDP (4 action potentials at $30 \mathrm{~Hz}$ : pre-then-post, $116 \pm$ $4 \% ; p=0.006 ; n=7$; post-then-pre, $56 \pm$ $10 \% ; p=0.014 ; n=5$; one action potential: pre-then-post, $116 \pm 2 \% ; p=0.001$ $n=6$; post-then-pre, $54 \pm 8 \% ; p=$ $0.0002 ; n=10)$. Together, these results indicate that adrenergic receptors enable Hebbian postsynaptic STDP of excitatory synapses onto SOM cells, in a similar manner as in FS-PV and pyramidal cells.

\section{Discussion}

Multiple rules and mechanisms for associative plasticity of glutamatergic inputs onto inhibitory interneurons have been reported in several brain regions. Here we report that in visual cortex: (1) the induction of bidirectional STDP in the two principal types of interneurons is Hebbian; (2) it requires neuromodulatory activity; and (3) STDP in FS-PV cells has a critical period that is delayed relative to other maturational processes. Importantly, in visual cortex, the rules of induction and neuromodulation of STDP are common to pyramidal and interneurons. We surmise that this condition facilitates the maintenance of an excitation/inhibition balance while allowing the circuitry to reorganize during development.

Despite the richness of rules reported for associative plasticity in interneurons (Fino and Venance, 2010; Lamsa et al., 2010; Kullmann et al., 2012), in cortex bidirectional Hebbian mechanisms have only been documented for low threshold interneurons (Lu et al., 2007). Thus, ours is the first demonstration of Hebbian bidirectional STDP in cortical FS-PV cells, the most abundant and best characterized type of cortical interneuron (Xu et al., 2010). In pyramidal neurons, Hebbian STDP is understood 
as a simple consequence of the voltage dependence of the activation of NMDARs. During the induction of tLTP, the delayed postsynaptic spike provides depolarization that boosts NMDAR activation and increases the concentration of intracellular $\mathrm{Ca}^{+2}$ to the threshold for tLTP (Shouval et al., 2010). However, the induction mechanism for postsynaptic tLTD is less clear, and several different mechanisms have been proposed to mediate this phenomenon in pyramidal cells (Froemke et al., 2010; Shouval et al., 2010). We found that, in the FS-PV cells, the induction of both Hebbian tLTP and tLTD requires intracellular $\mathrm{Ca}^{2+}$ and the activation of mGluR5, but not the activation of NMDA receptors.

How the temporal relationship between presynaptic and postsynaptic activation is detected and coded into $\mathrm{Ca}^{2+}$ signals specific for tLTP and tLTD in FS cells remains to be determined. One plausible mechanism is that a voltagedependent source of external $\mathrm{Ca}^{2+}$, along with activation of mGluR5, serves as a coincidence detector, for instance, by coactivating phospholipase $\mathrm{C}$ (Hashimotodani et al., 2005). Candidates for the external $\mathrm{Ca}^{2+}$ source are VGCCs and $\mathrm{Ca}^{2+}$-permeable AMPA receptors (CP-AMPARs), which have been implicated in STDP of hippocampal interneurons (Lamsa et al., 2007; Szabo et al., 2012). In visual cortex, FS cells express not only VGCCs but also CP-AMPARs, as the blocker NASPM $(250 \mu \mathrm{M})$ strongly reduces the EPSC amplitude (25.5 \pm $5.8 \%, n=4, p<0.001$; data not shown). However, the strong inward rectification of CP-AMPAR makes them more suitable for implementing anti-Hebbian rules of synaptic plasticity (Lamsa et al., 2007). Finally, the recently reported voltage dependence of mGluR output (Bezanilla, 2008) raises an intriguing possibility that the detection of presynaptic and postsynaptic coincidence might be mediated solely by mGluRs. In any event, regardless of the particular mechanism, our results demonstrate, for the first time, that a Hebbian rule for bidirectional STDP can be implemented independently of NMDAR activation.

In cortical pyramidal cells, G-protein-coupled receptors gate and control the polarity of STDP in a pull-push manner: Gscoupled receptors promote LTP at the expense of LTD and Gqcoupled receptors promote LTD over LTP (Choi et al., 2005; Seol et al., 2007; Zhang et al., 2009; Huang et al., 2012). Our present results suggest that this pull-push model can be generalized to multiple cell types, as we report a similar gating and control of STDP by adrenergic receptors in FS-PV and SOM cells. Indeed, as previously reported for pyramidal cell (Seol et al., 2007; Huang et al., 2012), the activation of $\beta$-adrenergic receptors (coupled to Gs) promotes an LTP-only state in both FS-PV and SOM cells. Notably, however, in pyramidal cells, tLTP depends on NMDAR activation (Seol et al., 2007), whereas in FS-PV cells, it depends on mGluRs (Fig. 3). The same effects in synapses that differ in induction mechanisms suggest that neuromodulation occurs downstream of the induction step. This observation dovetails nicely with the notion that, in pyramidal cells, neuromodulation

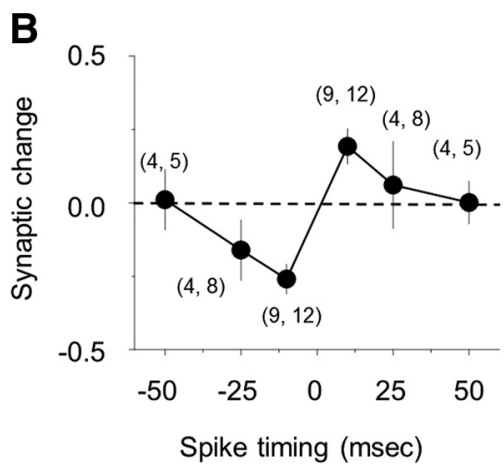

D

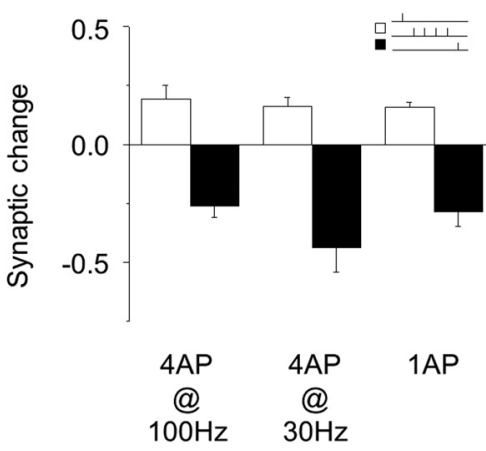

Figure 4. Adrenergic stimulation enables STDP in SOM interneurons. $\boldsymbol{A}$, Coactivation of $\alpha 1$ - and $\beta$-adrenergic receptors enables STDP in SOM interneurons, whereas coactivation of $\alpha 1$ - and $\beta$-adrenergic receptors pairing with postsynaptic burst alone induced no long-lasting change (gray circles). $\boldsymbol{B}$, The polarity and magnitude of STDP induced with the agonist mixture depend on Reducing the number and frequency of action potentials during the pairings reduces, but does not prevent, the induction of LTP, and it does not affect LTD induction. The number of experiments is indicated in parentheses. Data are mean \pm SEM.

of LTP and LTD is independent of changes in NMDAR and results from priming the AMPAR trafficking through AMPA receptor phosphorylation (Seol et al., 2007; Huang et al., 2012).

The diversity of rules and mechanisms of plasticity in interneurons is usually attributed to the functional and structural diversity of this group. However, different forms of plasticity have been reported for the same cell type. For example, in CA1 stratum radiatum interneurons, $\theta$ burst stimulation has been reported to induce LTD (McMahon and Kauer, 1997) or LTP (Nissen et al., 2010). Similarly, in cortex, presynaptic and postsynaptic mechanisms have been described for LTP in the highly overlapping groups of low-threshold spiking and SOM cells (Chen et al., 2009). Neuromodulation of NMDAR-dependent and independent forms of plasticity might contribute to the diversity of plasticity in interneurons. In particular, this may explain why different STDP rules are observed in the same cell type. It is well established that slice preparation affects the basal levels of AMPAR phosphorylation (Ho et al., 2004), which in turn may alter the need of neuromodulators for STDP (Edelmann and Lessmann, 2011). Thus, differences in endogenous levels of neuromodulators across laboratories along with different responsiveness to neuromodulation across interneurons might increase the apparent diversity of plasticity rules. For example, it was previously reported that SOM cells express both tLTP and tLTD, whereas FS cells express only tLTD (Lu et al., 2007). However, we have now demonstrated that, upon $\beta$-adrenergic stimulation, FS-PV cells are able to undergo tLTP (Fig. 2). Moreover, in accordance with the pull-push model, in the same FS-PV cells, the same stimulation paradigm can result in tLTP, tLTD, or no 
change at all, depending on the activation of $\alpha$ - or $\beta$-adrenergic receptors. This diversity of outcomes, even within the same cell type, suggests that some of the diversity of STDP rules may result from differences in the state of neuromodulation rather than intrinsic differences in the plasticity mechanisms.

Cortical interneurons, in particular FS cells, are considered essential for controlling experience-dependent cortical remodeling during postnatal development (Jiang et al., 2005; Kuhlman et al., 2010). Their role in postnatal plasticity is also supported by the modifiability of their receptive field properties (Kameyama et al., 2010; Kuhlman et al., 2011) and the clear critical period for the plasticity of their excitatory inputs (Fig. 2). However, FS cells are also critical for visual processing. FS cells, which provide the bulk of feedforward and feedback perisomatic inhibition (Martin, 2002), are essential for control of the rate and timing of cortical firing (Pouille and Scanziani, 2001; Kuhlman et al., 2010), and in V1 they have been implicated in shaping contrast sensitivity (Atallah et al., 2012) and orientation tuning (Ferster and Miller, 2000; Lee et al., 2012; Li et al., 2012). This raises the issue that preservation of cortical functionality during developmental remodeling requires maintaining an adequate excitation/inhibition balance. Indeed, in the somatosensory cortex, there is evidence that sensory deprivation induces coordinated changes in the excitatory inputs onto pyramidal and FS (House et al., 2011). Our demonstration of Hebbian STDP in FS-PV cells has an important implication in this regard. A common set of rules for the neuromodulation of STDP of excitatory inputs to pyramidal and FS cells might promote the maintenance of the cortical E/I balance during experience-dependent plasticity because, on average, both cell types will undergo changes in the same polarity.

\section{References}

Ascoli GA, Alonso-Nanclares L, Anderson SA, Barrionuevo G, BenavidesPiccione R, Burkhalter A, Buzsáki G, Cauli B, Defelipe J, Fairén A, Feldmeyer D, Fishell G, Fregnac Y, Freund TF, Gardner D, Gardner EP, Goldberg JH, Helmstaedter M, Hestrin S, Karube F, et al. (2008) Petilla terminology: nomenclature of features of GABAergic interneurons of the cerebral cortex. Nat Rev Neurosci 9:557-568. CrossRef Medline

Atallah BV, Bruns W, Carandini M, Scanziani M (2012) Parvalbuminexpressing interneurons linearly transform cortical responses to visual stimuli. Neuron 73:159-170. CrossRef Medline

Bezanilla F (2008) How membrane proteins sense voltage. Nat Rev Mol Cell Biol 9:323-332. CrossRef Medline

Castillo PE, Chiu CQ, Carroll RC (2011) Long-term plasticity at inhibitory synapses. Curr Opin Neurobiol 21:328-338. CrossRef Medline

Chattopadhyaya B, Di Cristo G, Higashiyama H, Knott GW, Kuhlman SJ, Welker E, Huang ZJ (2004) Experience and activity-dependent maturation of perisomatic GABAergic innervation in primary visual cortex during a postnatal critical period. J Neurosci 24:9598-9611. CrossRef Medline

Chen HX, Jiang M, Akakin D, Roper SN (2009) Long-term potentiation of excitatory synapses on neocortical somatostatin-expressing interneurons. J Neurophysiol 102:3251-3259. CrossRef Medline

Choi SY, Chang J, Jiang B, Seol GH, Min SS, Han JS, Shin HS, Gallagher M, Kirkwood A (2005) Multiple receptors coupled to PLC gate LTD in visual cortex. J Neurosci 25:11433-11443. CrossRef Medline

Dan Y, Poo MM (2004) Spike timing-dependent plasticity of neural circuits. Neuron 44:23-30. CrossRef Medline

Edelmann E, Lessmann V (2011) Dopamine modulates spike timingdependent plasticity and action potential properties in CA1 pyramidal neurons of acute rat hippocampal slices. Front Synaptic Neurosci 3:6. CrossRef Medline

Feldman DE (2012) The spike-timing dependence of plasticity. Neuron 75: 556-571. CrossRef Medline

Feldman DE, Nicoll RA, Malenka RC (1999) Synaptic plasticity at thalamocortical synapses in developing rat somatosensory cortex: LTP, LTD, and silent synapses. J Neurobiol 41:92-101. CrossRef Medline
Ferster D, Miller KD (2000) Neural mechanisms of orientation selectivity in the visual cortex. Annu Rev Neurosci 23:441-471. CrossRef Medline

Fino E, Venance L (2010) Spike-timing dependent plasticity in the striatum. Front Synaptic Neurosci 2:6. CrossRef Medline

Fino E, Venance L (2011) Spike-timing dependent plasticity in striatal interneurons. Neuropharmacology 60:780-788. CrossRef Medline

Freund TF, Katona I (2007) Perisomatic inhibition. Neuron 56:33-42. CrossRef Medline

Froemke RC, Debanne D, Bi GQ (2010) Temporal modulation of spiketiming-dependent plasticity. Front Synaptic Neurosci 2:19. CrossRef Medline

Gu Z, Yakel JL (2011) Timing-dependent septal cholinergic induction of dynamic hippocampal synaptic plasticity. Neuron 71:155-165. CrossRef Medline

Gu Z, Lamb PW, Yakel JL (2011) Cholinergic coordination of presynaptic and postsynaptic activity induces timing-dependent hippocampal synaptic plasticity. J Neurosci 32:12337-12348. CrossRef Medline

Guo Y, Huang S, de Pasquale R, McGehrin K, Lee HK, Zhao K, Kirkwood A (2012) Dark exposure extends the integration window for spike-timingdependent plasticity. J Neurosci 32:15027-15035. CrossRef Medline

Hashimotodani Y, Ohno-Shosaku T, Tsubokawa H, Ogata H, Emoto K, Maejima T, Araishi K, Shin HS, Kano M (2005) Phospholipase Cbeta serves as a coincidence detector through its $\mathrm{Ca}^{2+}$ dependency for triggering retrograde endocannabinoid signal. Neuron 45:257-268. CrossRef Medline

Ho OH, Delgado JY, O’Dell TJ (2004) Phosphorylation of proteins involved in activity-dependent forms of synaptic plasticity is altered in hippocampal slices maintained in vitro. J Neurochem 91:1344-1357. CrossRef Medline

House DR, Elstrott J, Koh E, Chung J, Feldman DE (2011) Parallel regulation of feedforward inhibition and excitation during whisker map plasticity. Neuron 72:819-831. CrossRef Medline

Huang S, Treviño M, He K, Ardiles A, de Pasquale R, Guo Y, Palacios A, Huganir R, Kirkwood A (2012) Pull-push neuromodulation of LTP and LTD enables bidirectional experience-induced synaptic scaling in visual cortex. Neuron 73:497-510. CrossRef Medline

Huang ZJ, Di Cristo G, Ango F (2007) Development of GABA innervation in the cerebral and cerebellar cortices. Nat Rev Neurosci 8:673-686. CrossRef Medline

Jiang B, Huang ZJ, Morales B, Kirkwood A (2005) Maturation of GABAergic transmission and the timing of plasticity in visual cortex. Brain Res Brain Res Rev 50:126-133. CrossRef Medline

Jiang B, Treviño M, Kirkwood A (2007) Sequential development of longterm potentiation and depression in different layers of the mouse visual cortex. J Neurosci 27:9648-9652. CrossRef Medline

Jiang B, Sohya K, Sarihi A, Yanagawa Y, Tsumoto T (2010a) Laminarspecific maturation of GABAergic transmission and susceptibility to visual deprivation are related to endocannabinoid sensitivity in mouse visual cortex. J Neurosci 30:14261-14272. CrossRef Medline

Jiang B, Huang S, de Pasquale R, Millman D, Song L, Lee HK, Tsumoto T, Kirkwood A (2010b) The maturation of GABAergic transmission in visual cortex requires endocannabinoid-mediated LTD of inhibitory inputs during a critical period. Neuron 66:248-259. CrossRef Medline

Kameyama K, Sohya K, Ebina T, Fukuda A, Yanagawa Y, Tsumoto T (2010) Difference in binocularity and ocular dominance plasticity between GABAergic and excitatory cortical neurons. J Neurosci 30:1551-1559. CrossRef Medline

Kuhlman SJ, Lu J, Lazarus MS, Huang ZJ (2010) Maturation of GABAergic inhibition promotes strengthening of temporally coherent inputs among convergent pathways. PLoS Comput Biol 6:e1000797. CrossRef Medline

Kuhlman SJ, Tring E, Trachtenberg JT (2011) Fast-spiking interneurons have an initial orientation bias that is lost with vision. Nat Neurosci 14: 1121-1123. CrossRef Medline

Kullmann DM, Moreau AW, Bakiri Y, Nicholson E (2012) Plasticity of inhibition. Neuron 75:951-962. CrossRef Medline

Lamsa KP, Heeroma JH, Somogyi P, Rusakov DA, Kullmann DM (2007) Anti-Hebbian long-term potentiation in the hippocampal feedback inhibitory circuit. Science 315:1262-1266. CrossRef Medline

Lamsa KP, Kullmann DM, Woodin MA (2010) Spike-timing dependent plasticity in inhibitory circuits. Front Synaptic Neurosci 2:8. CrossRef Medline

Lee HK, Kirkwood A (2011) AMPA receptor regulation during synaptic 
plasticity in hippocampus and neocortex. Semin Cell Dev Biol 22:514520. CrossRef Medline

Lee SH, Kwan AC, Zhang S, Phoumthipphavong V, Flannery JG, Masmanidis SC, Taniguchi H, Huang ZJ, Zhang F, Boyden ES, Deisseroth K, Dan Y (2012) Activation of specific interneurons improves V1 feature selectivity and visual perception. Nature 488:379-383. CrossRef Medline

Li YT, Ma WP, Li LY, Ibrahim LA, Wang SZ, Tao HW (2012) Broadening of inhibitory tuning underlies contrast-dependent sharpening of orientation selectivity in mouse visual cortex. J Neurosci 32:16466-16477. CrossRef Medline

Lu JT, Li CY, Zhao JP, Poo MM, Zhang XH (2007) Spike-timing-dependent plasticity of neocortical excitatory synapses on inhibitory interneurons depends on target cell type. J Neurosci 27:9711-9720. CrossRef Medline

Markram H, Gerstner W, Sjöstrom PJ (2011) A history of spike-timingdependent plasticity. Front Synaptic Neurosci 3:4. CrossRef Medline

Martin KA (2002) Microcircuits in visual cortex. Curr Opin Neurobiol 12: 418-425. CrossRef Medline

McMahon LL, Kauer JA (1997) Hippocampal interneurons express a novel form of synaptic plasticity. Neuron 18:295-305. CrossRef Medline

Morales B, Choi SY, Kirkwood A (2002) Dark rearing alters the development of GABAergic transmission in visual cortex. J Neurosci 22:80848090. Medline

Nissen W, Szabo A, Somogyi J, Somogyi P, Lamsa KP (2010) Cell typespecific long-term plasticity at glutamatergic synapses onto hippocampal interneurons expressing either parvalbumin or CB1 cannabinoid receptor. J Neurosci 30:1337-1347. CrossRef Medline

Oliva AA Jr, Jiang M, Lam T, Smith KL, Swann JW (2000) Novel hippocampal interneuronal subtypes identified using transgenic mice that express green fluorescent protein in GABAergic interneurons. J Neurosci 20: 3354-3368. Medline

Pouille F, Scanziani M (2001) Enforcement of temporal fidelity in pyrami- dal cells by somatic feed-forward inhibition. Science 293:1159-1163. CrossRef Medline

Richards BA, Aizenman CD, Akerman CJ (2010) In vivo spike-timingdependent plasticity in the optic tectum of Xenopus laevis. Front Synaptic Neurosci 2:7. CrossRef Medline

Sarihi A, Jiang B, Komaki A, Sohya K, Yanagawa Y, Tsumoto T (2008) Metabotropic glutamate receptor type 5-dependent long-term potentiation of excitatory synapses on fast-spiking GABAergic neurons in mouse visual cortex. J Neurosci 28:1224-1235. CrossRef Medline

Seol GH, Ziburkus J, Huang S, Song L, Kim IT, Takamiya K, Huganir RL, Lee HK, Kirkwood A (2007) Neuromodulators control the polarity of spiketiming-dependent synaptic plasticity. Neuron 55:919-929. CrossRef Medline

Shouval HZ, Wang SS, Wittenberg GM (2010) Spike timing dependent plasticity: a consequence of more fundamental learning rules. Front Comput Neurosci 4.

Song S, Abbott LF (2001) Cortical development and remapping through spike timing-dependent plasticity. Neuron 32:339-350. CrossRef Medline

Song S, Miller KD, Abbott LF (2000) Competitive Hebbian learning through spike-timing-dependent synaptic plasticity. Nat Neurosci 3:919926. CrossRef Medline

Szabo A, Somogyi J, Cauli B, Lambolez B, Somogyi P, Lamsa KP (2012) Calcium-permeable AMPA receptors provide a common mechanism for LTP in glutamatergic synapses of distinct hippocampal interneuron types. J Neurosci 32:6511-6516. CrossRef Medline

Xu X, Roby KD, Callaway EM (2010) Immunochemical characterization of inhibitory mouse cortical neurons: three chemically distinct classes of inhibitory cells. J Comp Neurol 518:389-404. CrossRef Medline

Zhang JC, Lau PM, Bi GQ (2009) Gain in sensitivity and loss in temporal contrast of STDP by dopaminergic modulation at hippocampal synapses. Proc Natl Acad Sci U S A 106:13028-13033. CrossRef Medline 